\title{
The Real Origin of Alice in Wonderland Syndrome in Childhood is still Unknown: Does Physical Abuse Play a Major Role?
}

\author{
Stefan Bittmann* \\ *Department of Pediatrics, Ped Mind Institute, Germany
}

*Corresponding author: Stefan Bittmann MD, MA, Department of Pediatrics, Ped Mind Institute, Hindenburgring 448599 Gronau, Germany, Tel: 0049-2565-97325; Fax: 0049-2565-97324; Email: stefanbittmann@gmx.de

\section{Keywords: Wonderland syndrome; H1N1 influenza infection; Brain tumor}

Received Date: January 05, 2019; Accepted Date: January 08, 2019; Published Date: January 15, 2019

\section{Editorial}

Lewis Carroll wrote in 1864 the novel of Alice in Wonderland "Alice`s Adventures under Ground" [1]. The British psychiatrist John Todd (1914-1987) described the curious condition of micro-and macrosomatognosia, altered perceptions of body image, and described it as Alice in Wonderland Syndrome. John Todd described it 1955 and gave it the literary name in his publication.

The real origin is still unknown. AIWS was described in association with many different infectious diseases like malaria, zika virus, varicella induced optical neuromyelitis, lyme disease, H1N1 influenza infection and mononucleosis. Other entities like complex partial epilepsy, migraine, and acute disseminated encephalomyelitis, drug abuse like LSD or montelukast are further associated drug correlations relating to AIWS seizures. Moreover recent articles describe postoperative AIWS seizures after ventriculoatrial shunt operation in hydrocephalus and in patients with brain tumor (glioblastoma). Recent publications describe the curious aspect of AIWS seizures chronically correlating with sexual abuse [2-5].

In this publication, two elder women describing their horrific experience with sexual abuse and chronically relating AIWS seizures after many years [2-5].

Disordered body perceptions induce anxiety and fear, sometimes for many years in early childhood and can influence the normal development of child in the family and their surroundings.

The real origin of this curious disease of Alice in Wonderland syndrome is still unknown. Recent studies shed light on aspects on physical and sexual abuse, which should be underpinned by further cases and research.

\section{References}

1. Cohen MN (1996) Lewis Carroll. A biography. Reprint. Vintage Books, New York 1996.

Citation: Stefan Bittmann, The Real Origin of Alice in Wonderland Syndrome in Childhood is still Unknown: does Physical Abuse Play a Major Role?. J Clin Cases Rep 2(2): 41-42. DOI: https://doi.org/10.46619/joccr.2019.2-1036

(C) 2019 Tridha Scholars. 
http://www.tridhascholars.org | April-2019

2. Bittmann S (2018) The clue to the unknown origin of Alice in wonderland in children?. Pediatric Research and Child Health 1: 001.

3. Bittmann S, Luchter E, Villalon G (2018) Does sexual abuse play a causative role in Alice in wonderland syndrome in childhood? A help screaming from internet. Journal of Perinatology \& Clinical Pediatrics: JPCP-104.

4. Bittmann S (2018) Abuse in children: Indicator of failure in relationship?. Advances in Pediatric Research 5: 16.

5. Bittmann S (2018) Alice in Wonderland Syndrome in childhood: Abuse is the root? Journal of Pediatric Diseases 2(2): 1-2. 